\title{
Cavitation Erosion and Wear Mechanisms of AlTiN and TiAlN Films Deposited on Stainless Steel Substrate
}

\author{
Mirosław Szala 1,*, Mariusz Walczak ${ }^{1}$, Kamil Pasierbiewicz ${ }^{2,3}$ and Mariusz Kamiński ${ }^{4}$ \\ 1 Department of Materials Engineering, Faculty of Mechanical Engineering, Lublin University of \\ Technology, Nadbystrzycka 36D, 20-618 Lublin, Poland; m.walczak@pollub.pl \\ 2 Department of Materials Engineering, Faculty of Mechanical Engineering, Lublin University of \\ Technology, Nadbystrzycka 36D, 20-618 Lublin, Poland; pasierbiewicz.k@gmail.com \\ 3 Faculty of Transport and Computer Science, University of Economics and Innovation, Projektowa 4, \\ 20-209 Lublin, Poland \\ 4 Department of Automotive Vehicles, Faculty of Mechanical Engineering, Lublin University of Technology, \\ Nadbystrzycka 36D, 20-618 Lublin, Poland; mariusz.kaminski@pollub.pl \\ * Correspondence: m.szala@pollub.pl; Tel.: +48-815-384-209
}

Received: 15 February 2019; Accepted: 15 March 2019; Published: 15 March 2019

\begin{abstract}
Stainless steel grade AISI 304 is one of the most widespread modern structural material, alas its sliding wear and cavitation wear resistance are limited. Thus, AlTiN and TiAlN coatings can be deposited for increasing the resistance to wear of stainless steel components. The aim of the work was to investigate the cavitation erosion and sliding wear mechanisms of magnetron sputtered AlTiN and TiAlN coatings deposited on SS304 stainless steel. AlTiN and TiAlN films were deposited on a stainless steel substrate grade AISI 304. Films surface morphology and structure were examined using a profilometer, light optical microscope (LOM) and scanning electron microscope (SEM). The mechanical properties (hardness, elastic modulus) were tested by nanoindentation tester. The adhesion of deposited coatings was determined by means of the scratch test and Rockwell test. Cavitation erosion tests were performed according to ASTM G32 (vibratory apparatus) with stationary specimen procedure. Sliding wear tests were conducted using a nanotribo testes i.e. ball-on-disc apparatus. Wear mechanisms are strongly contingent upon the structure and morphology of the tested materials. In relation to stainless steel substrate, the PVD films present a superior resistance to sliding wear and cavitation erosion. Higher resistance was noticed for AlTiN than for TiAlN film, mainly due to its superior hardness and elastici modulus. Cavitation erosion mechanism of both, AlTiN and AlTiN coatings is prone to embrittlement, imputable to fatigue processes that result in coating rupture and spallation that consist in coating fragmentation, formation of pits and finally detachment from the substrate. In contrary to PVD coatings, steel substrate is characterized by developed cavitation erosion wear with roughened surface and plastically deformed, semi-brittle, eroded surface. Sliding wear of thin films is based on microploughing mechanism. For stainless steel adhesive sliding wear mode and plastic deformation with smearing, material transfer and grooving were observed. It was confirmed that various fluid machinery components made from austenitic stainless steel that undergo cavitation erosion, can be prevented by deposition of AlTiN and TiAlN films.
\end{abstract}

Keywords: cavitation erosion; sliding wear; thin film; AlTiN; TiAlN; mechanical properties; stainless steel; adhesion 


\section{Introduction}

Being resistant to corrosion and having satisfactory mechanical properties, sufficient weldability and good formidability, stainless steel (SS) grade AISI 304 is assumed to be one of the most widespread modern structural material [1-6]. However, its sliding wear and cavitation erosion resistance (CER) are limited. It can be improved by deposition of different systems of hard coatings, such as TiN, CrN, TiAlN or AlTiN, or even by depositing stainless steel coating enriched with silver $[3,7,8]$. Especially, modern types of TiAlN or AlTiN hard films are commonly used for manufacturing the machining tools, in order to reduce tribochemical or adhesive wear [9-11]. In other words, AlTiN and TiAlN coatings seem beneficial for increasing the resistance to wear of stainless steel components, which are exposed to severe wear processes. Moreover, the universal coatings trinary element system such as TiAlN or AlTiN can not only improve tribological substrate properties but could be also used for creating a protective layer on components subjected to cavitation erosion - and thus improving the erosion resistance of steel components.

On the other hand, literature reports mostly binary coating systems CE (cavitation erosion) result and acknowledged that hard thin films such as TiN, CrN present superior CER to SS304 substrate [7,12]. Also, a ternary film system presents usually superior mechanical properties to binary one. Besides, Krella [7] stated that not only films properties but also substrate mechanical properties are crucial for CER or PVD coatings. In addition, there are reports on the research in the field of CE of aluminum alloy coated with TiAlN thin film. However, TiAlN or AlTiN cavitation erosion mechanism is not presented in relation to SS304 substrate properties. Also, there is a limited number of reports comparing TiAlN or AlTiN coatings properties, in relation to its cavitation erosion resistance, and investigating its wear CE wear mechanism.

The aim of this work was to study the cavitation erosion and sliding wear mechanisms of magnetron sputtered AlTiN and TiAlN coatings deposited on stainless steel substrate. The paper is an introduction to CER testing of films deposited on various metal alloy substrates, and a quantitative determination of its CER. Thus, the thin films, such as TiAlN or AlTiN, its application in fluid machinery, precise mechanics components and engines in cavitation wear prevention are proposed.

\section{Materials and Methods}

AlTiN and TiAlN films were deposited by DC magnetron sputtering process on a stainless steel substrate grade AISI 304 to obtain approx. $3 \mu \mathrm{m}$ thick layers. The substrate roughness measured with ContourGT-X 3D Optical Profiler (Bruker Corporation, USA) was less than Sa $=0.2 \mu$ m. After deposition, several properties were identified. The coatings thickness was examined with Calotester (surface testing), as well as with metallographic investigations conducted on the samples' sections using a light optical microscopy (LOM, Nikon MA200, Nikon Corporation). Scanning electron microscopy (SEM, Quanta, Thermo Fisher Scientific-FEI, and Phenom World ProX, BSE and topographic modes, Phenom World) and optical profiler were employed to study the coatings structure and surface morphology. Deposited films and substrate mechanical properties (hardness, elastic modulus) of nitride coatings on the substrate, were tested by means of Ultra Nanoindentation Tester (Anton Paar GmbH, Germany) with procedures presented in [13]. It should be emphasized that, from 100 indentations only approx. $80 \%-90 \%$ of results were considered to estimate the mechanical films properties. The values of hardness and elastic modulus were calculated from the load-displacement curves according to the Oliver Pharr method. The adhesion of deposited coatings was determined by means of the scratch testing and Rockwell adhesion tests. Scratch tests were performed on Micro Combi Tester (Anton Paar GmbH, Germany), according to the ASTM C1624-05 standard for ceramic coatings scratch testing, and Rockwell tests, according to VDI 3198 procedure.

Cavitation erosion and sliding wear tests were conducted for bare stainless steel grade SS304 (SS) and SS coated with PVD films. Cavitation erosion tests were performed according to ASTM G32 [14] (vibratory apparatus) with stationary specimen procedure. Test procedure was presented in previous work $[15,16]$ and the scheme of facility is presented in Figure 1. Submerged in distilled water, tip horn vibrations generate cavitation field that effects erosion specimen surface (Figure 1). 
In present study, a sonotrode tip with diameter $15.9 \mathrm{~mm}$ was used. Damaged samples were examined by weighting with a $0.1 \mathrm{mg}$ accuracy balance, roughness 3D profilometer and observed with SEMEDS and with use of optical microscopy (OM) with a stereoscope microscope Nikon SMZ 1500. Cavitation worn area was measured with the ImagePro computer image analysis software (Media Cybernetics, Inc., USA) at the OM photos. Further, $4.5 \mathrm{~h}$ of cavitation resulted in normalized cavitation erosion resistance for results obtained by samples weighing (mass loss), computer image analysis of worn surfaces (\% of damaged area) and surface roughness (Sa roughness parameter) measurements. Normalized cavitation erosion resistance was calculated by dividing the estimated indicators of SS304 by the estimated indicators of the AlTiN and TiAlN films. Additionally, a new attempt at describing the cavitation erosion effects on films was made, i.e. the nanoindentation results were carried out and analyzed at sample surfaces before and after cavitation erosion testing.

(Nano Tribometer, NTR2, Anton Paar GmbH) described in $[17,18]$. To simulate low frictionconditions, which relate to mostly limited loads of sliding in fluid machinery, the nano-tribo tests were carried out. As a counter sample, a WC ball with a diameter $0.5 \mathrm{~mm}$ was used. A load of $0.8 \mathrm{~N}$, sliding distance of $90 \mathrm{~m}$ and sliding radius of $5 \mathrm{~mm}$ were applied to the ball. As a result, friction coefficient $\mu$ for individual samples was determined. Next, the wear trace was measured using the Taylor Hobson Form Talysurf Intra profile measurement gauge. The measurements provided profilograms enabling determination of the wear factor $K$, see [19]. In addition, wear traces were analyzed with SEM so on wear mechanism was stated.

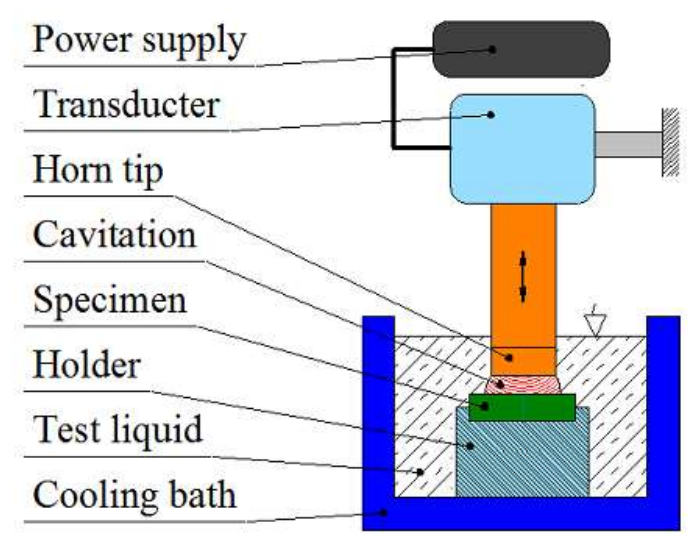

Figure 1. Design of vibratory apparatus for cavitation tests.

\section{Results and Discussion}

\subsection{Description of Films Properties in Relation to Stainless Steel Substrate}

Wear resistance of thin films should be discussed in relation to structure and properties of both, film and substrate. In present work, magnetron sputtered films thickness measured by Calotester agreed with cross-section metallographic investigation and was estimated as $\approx 2.7 \mu \mathrm{m}$ for TiAlN and $\approx 3.8 \mu \mathrm{m}$ for AlTiN. Coatings showed a dense compact structure (Figure 2) characterized by columnar growth, which according to Kalss [20] is typical for sputtering technology. Coating roughness measured by profilometer was lower than $0.2 \mu \mathrm{m}$ which corresponds with the surface preparation of the stainless steel substrate. Chemical composition of films was summarized in Table 1 and indicated that AlTiN contains more nitrogen than TiAlN film. It is evident that, chemical differences affect mechanical properties of the films and substrate-film performance. Therefore, higher average coating to SS substrate adhesion (Table 2) presents for AlTiN than TiAlN. However, while statistically analyzing the Lc2 values and scratch trace (Figures 3 and 4), a satisfying level of adhesion for both films can be stated. In Figure 3 a conformal cracking, cohesive failure and microcracks are visible and from Figure 4, it can be concluded that the main adhesive failure mode was observed as cohesive failure, spallation, tensile micro-cracking, followed by chipping failure mode of both AlTiN and TiAlN films, which is in accordance with results reported by Kulkarni and Sargade [10]. Additionally 
Figure 4 acknowledged finer cracking of TiAlN film than AlTiN which can be affected by variations in coatings elasticity modulus, films adhesion and cohesion. In Figure 5 it is clearly visible, that mechanical properties given by nanohardness measurements indicate superior hardness, in average higher for AlTiN (5271 HV) than for TiAlN (4897 HV), and films are comparable to elasticity modulus at level of AlTiN (758 GPa) and for TiAlN (796 GPa), which exceeded the steel substrate values 275 GPa. On the other hand, literature reports that cathodic arc deposited AlTiN and TiAlN films [21] present modulus on the level of $400 \mathrm{GPa}$. Differences between the result obtained in our study and presented by the literature can derive from magnetron sputtering technology resulting in coating columnar structure (Figure 2). Also, wrought (work hardened) metal substrate preparation affects deposited films morphology and obtained nano-measurement findings. Relatively high average value of stainless steel hardness $749 \mathrm{HV}$ could derive from wrought nature of the stainless steel rod (work hardened), from which test samples were cut-out. Also, it is worth adding, that it is difficult to compare nanohardness results with hardness measured with higher loads (macro hardness test). Nevertheless, findings obtained in the hardness measurements should be interpreted with caution. In contrary to the traditional hardness measurement techniques, e.g. Vickers hardness measurements which is explained in detail in work of Łępicka [13]. Moreover, obtained in this research hardness value are in range of results range reported by the referred above study.

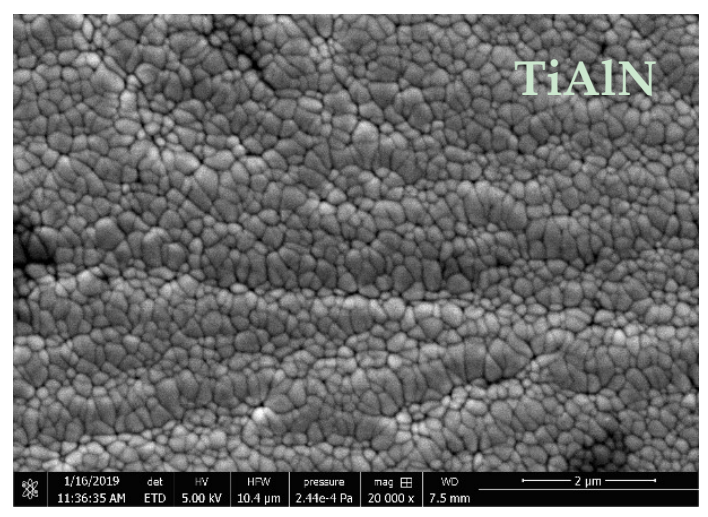

(a)

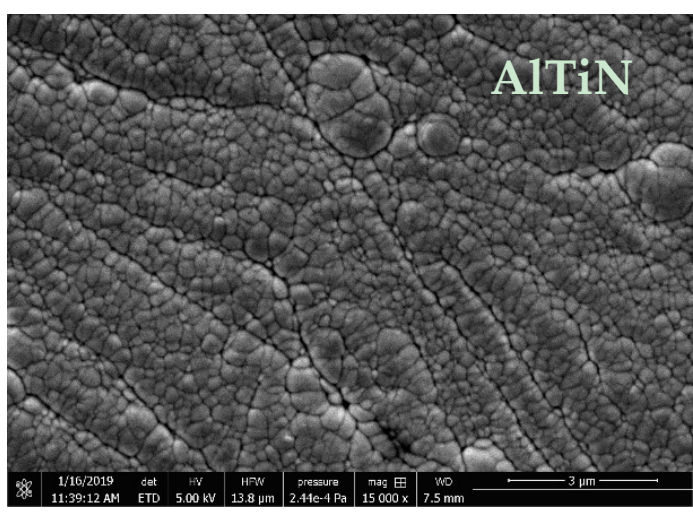

(b)

Figure 2. Surface of deposited PVD coatings: (a) TiAlN; (b) AlTiN, SEM.

Table 1. Results of SEM-EDS surface chemical composition spot analysis.

\begin{tabular}{cccccccc}
\hline \multirow{2}{*}{ Film } & Spot & \multicolumn{7}{c}{ Chemical Element } \\
\cline { 3 - 8 } & & Ti (wt \%) & Al(wt \%) & N(wt \%) & Ti (at \%) & Al(at \%) & N(at \%) \\
\hline \multirow{3}{*}{ TiAlN } & 1 & 52.93 & 30.63 & 16.43 & 32.39 & 33.25 & 34.36 \\
& 2 & 52.27 & 30.07 & 17.67 & 31.49 & 32.14 & 36.38 \\
& 3 & 50.20 & 31.10 & 18.70 & 29.66 & 32.59 & 37.75 \\
\hline \multirow{3}{*}{ AlTiN } & Average & 51.80 & 30.60 & 17.60 & 31.16 & 32.66 & 36.18 \\
& 1 & 41.93 & 35.63 & 22.43 & 23.06 & 34.77 & 42.17 \\
& 2 & 43.30 & 35.10 & 21.60 & 24.14 & 34.71 & 41.15 \\
& 3 & 44.97 & 35.47 & 19.57 & 25.73 & 36.00 & 38.27 \\
\hline
\end{tabular}

Table 2. Films critical loads estimated in scratch test (Figure 3): Lc1-first symptoms of cohesive failure (angular or parallel cracking), Lc2-beginning of adhesive failure (buckling, chipping, spalling, etc.), Lc3 - total failure of the coating or massive exposure of the substrate (mean \pm SD).

\begin{tabular}{cccc}
\hline Film & Lc1 [N] & Lc2 [N] & Lc3 [N] \\
\hline TiAlN & $0.91 \pm 0.54$ & $7.23 \pm 1.19$ & $15.38 \pm 3.43$ \\
AlTiN & $0.91 \pm 0.61$ & $8.87 \pm 2.40$ & $18.93 \pm 4.76$ \\
\hline
\end{tabular}




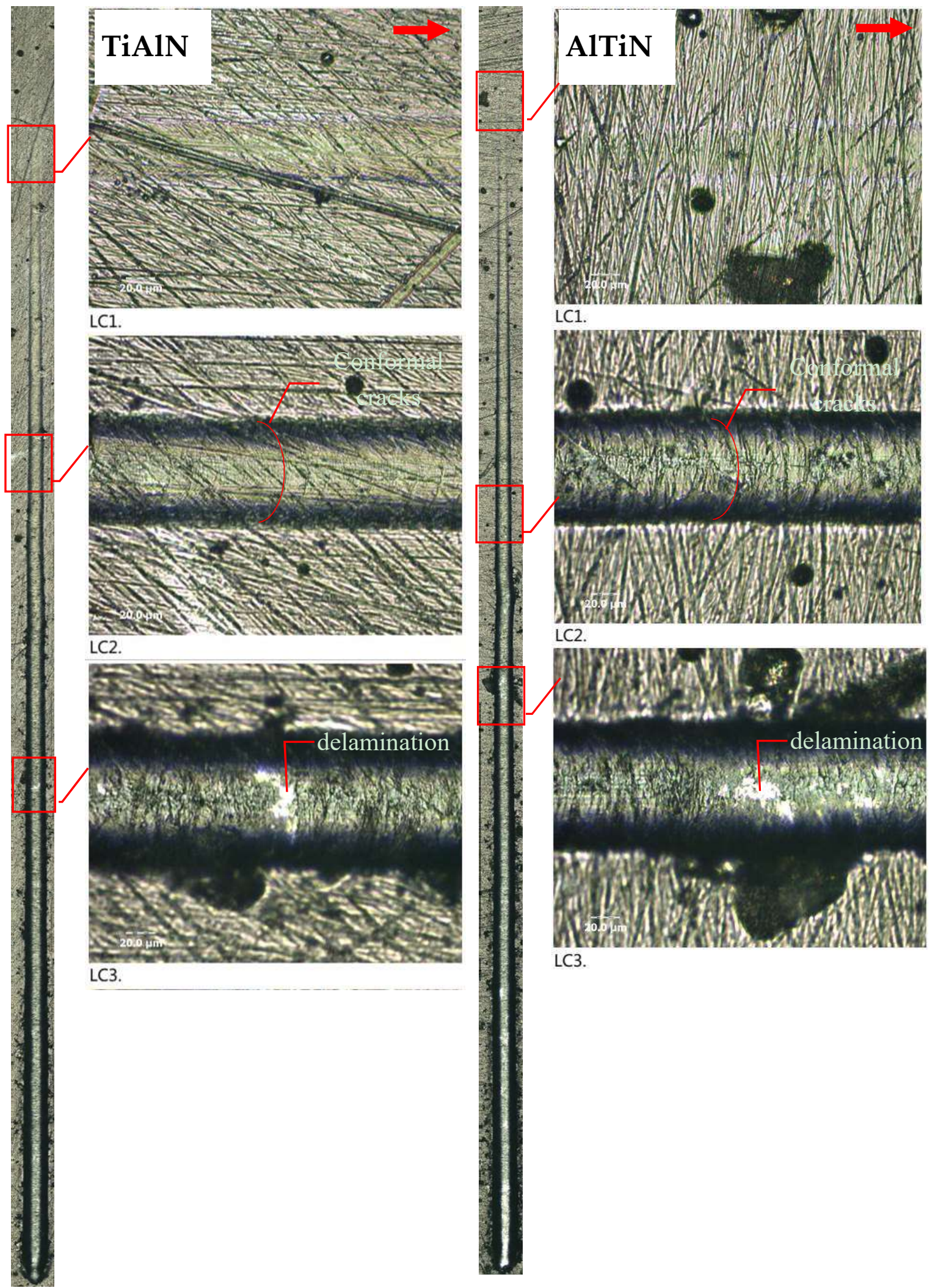

Figure 3. Scratch traces: (a) TiAlN; (b) AlTiN and enlarged characteristic areas of Lc1, Lc2 and Lc3. (total scratch trace $3 \mathrm{~mm}$ ). 

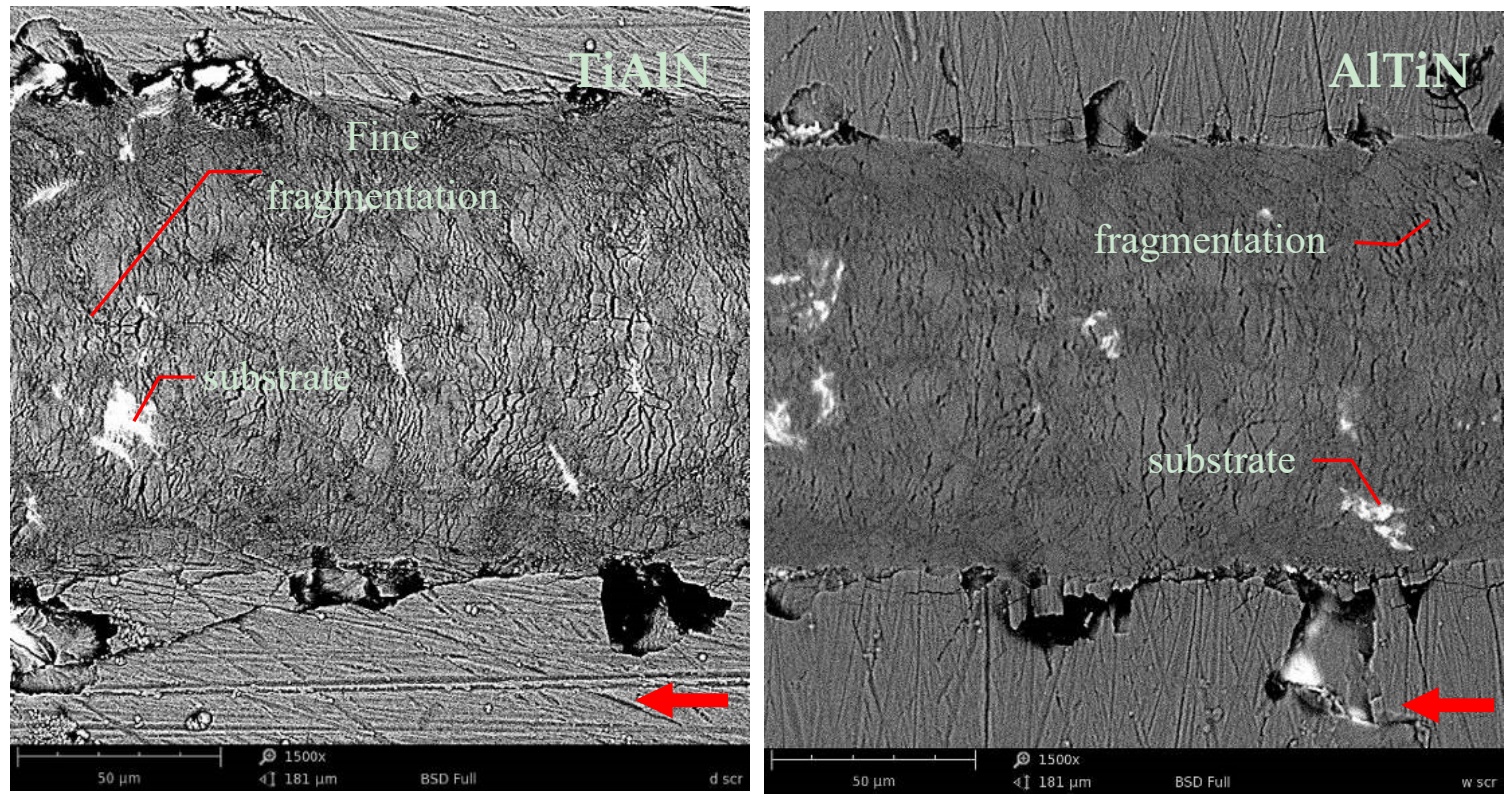

Figure 4. Comparison of films at the end of the scratch trace, direction of the scratch marked by an arrow, magnify. 1500×, SEM.
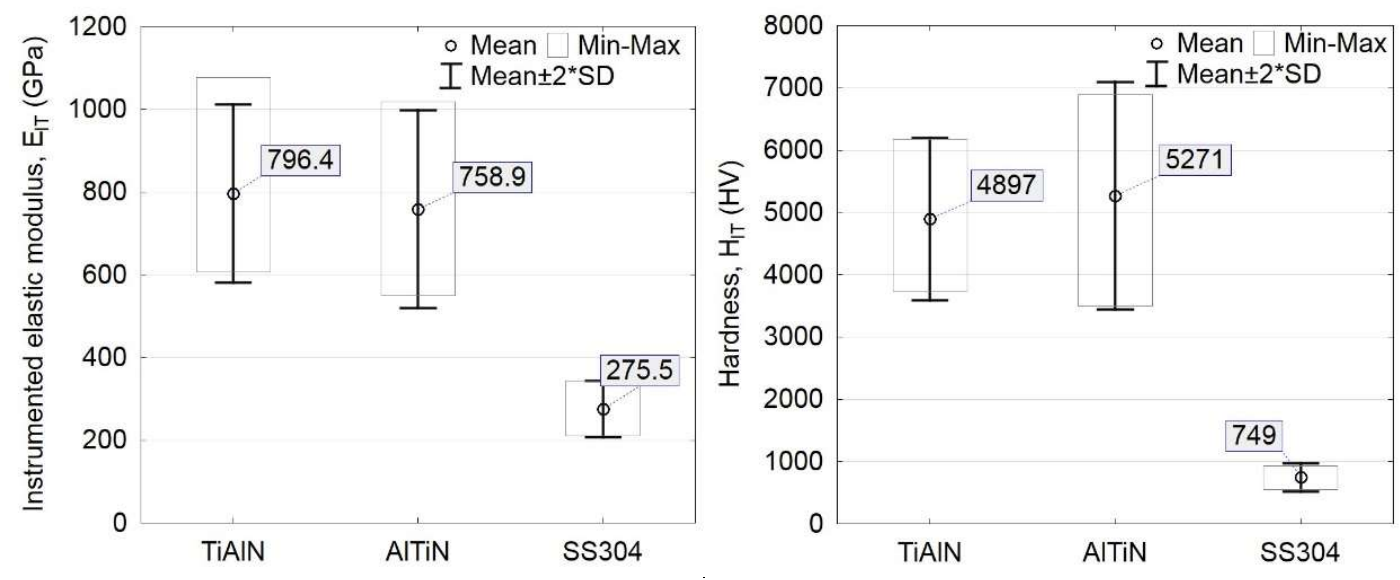

Figure 5. Elastic modulus and hardness of coated and bare SS304 samples.

\subsection{Cavitaiton Erosion}

The quantitative results of reference stainless steel grade SS304 and the magnetron sputtered AlTiN and TiAlN films deposited on SS304 substrate are given in Figure 6, while Figure 9 and Table 3 presents effect of CE on nanoindentation results, which is quite an original attempt in CER evaluation. Finally, qualitative description of mechanism of erosion is discussed on the basis of Figures 7 and 8.

All calculated parameters indicate that the highest CER presents AlTiN coating, see Figure 6. Tested films exhibit outstanding CER in relation to reference SS. These results are strongly influenced by coating thickness, mechanical properties and adhesion to substrate. TiAlN presents lower values of thickness, hardness, elastic modulus, as well as Lc2 value; thus, it can be deduced that these factors affect $\mathrm{CE}$ quantitative results. In addition, good enough correlations combining listed above properties and CER for TiN or CrN films were shown in works of Krella [7,22], yet triple element coatings have not been investigated and properties to CER should be elaborated.

It is also worth to mention, that among the structural material SS304 presents relatively high resistance to $\mathrm{CE}$ and is considered as one of the most popular $\mathrm{CE}$ rested materials. However, basing on the literature, as well as own research, its CER of SS can be stated as moderate (higher than Al-, 
Mg-, brass [23,24] and less than bronze, Ni- or Co-based alloys [25-27] or HVOF sprayed MCrAlY type coatings [28]).

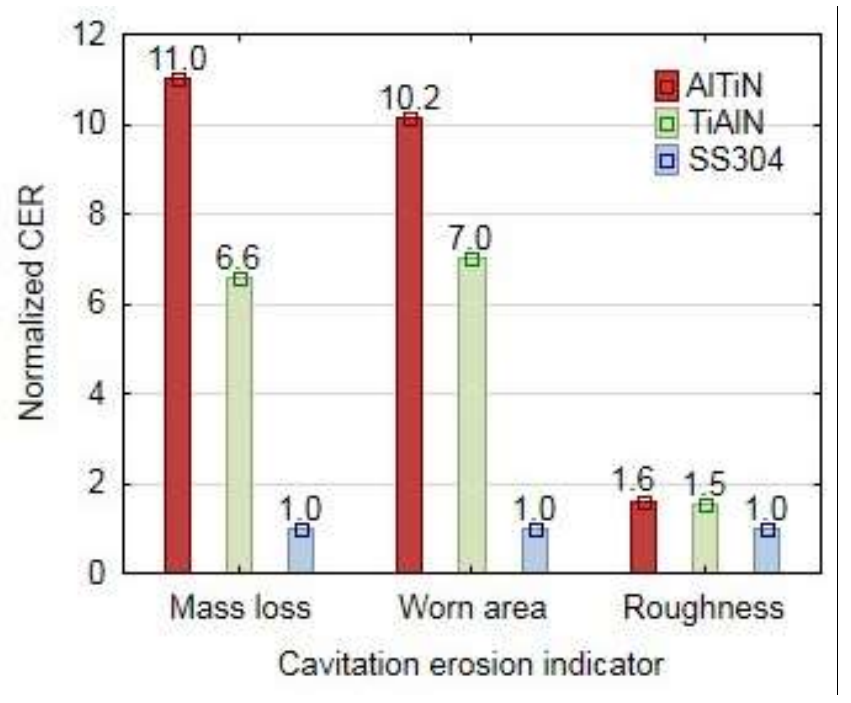

Figure 6. Normalized cavitation erosion resistance (CER) calculated in reference to SS304 based on mass loss (mg), portion of worn area (\%) and Sa roughness parameter $(\mu \mathrm{m}), 4.5 \mathrm{~h}$ of cavitation test.

\subsubsection{Mechanism of Cavitation Erosion Damage}

Figure 7a presents macroscopic view and Figure $7 \mathrm{~b}$ compares surface morphology of TiAlN, AlTiN and SS304 worn by cavitation erosion which estimated Sa roughness parameters equals 1.5 $\mu \mathrm{m}, 1.4 \mu \mathrm{m}$ and $2.3 \mu \mathrm{m}$, respectively. SEM photographs from Figure 8 illustrates details of cavitation erosion of tested materials. In general, comparison of worn surfaces agrees with quantitative data presented in Figure 6. TiAlN coating seems severely more damaged than AlTiN film, and both are less eroded than stainless steel reference material.

Literature survey indicates that there are limited reports comparing TiAlN or AlTiN coatings properties, in relation to its cavitation erosion resistance and investigating its wear CER mechanism. Figure 8 allows to describe the cavitation erosion mechanism of deposited films and discuss it with reference to SS substrate properties. Thus, after $4.5 \mathrm{~h}$ of testing random pits appeared in the film structure, and measurable mass loss was obtained. By depositing the hard films, incubation period of erosion elongates three times comparing to bare SS samples. This seems promising for increasing the operation time of real stainless steel components magnetron sputtered with TiAlN or AlTiN.

Generally, films are degraded by either the micro-jets or shock pressure waves that result in films rupture and spalling so on its CE wear mechanism presents a brittle manner. Comparison of cavitation worn TiAlN and AlTiN films, conducted in pits areas Figure 8, allows to claim that there is a higher level of fragmentation of TiAlN film than AlTiN. That could facilitate removal of fragmented TiAlN coating materials and accelerate its mass loss. It agrees with quantitative result Figure 6, i.e., higher than TiAlN normalized erosion resistance of AlTiN.

At first, cavitation impacts on films however, deposited TiAlN or AlTiN are much harder and brittle than metal alloy substrate, which causes steel substrate deformation and detachment of coating material, which is not able to follow the substrate deformation and due. Fatigue character of cavitation influence on solid surface is clearly visible in Figure 8. Coating is spalled and detached in random areas, proceeded by fatigue deformation of film. Once coating is detached, the SS substrate undergoes erosion. Finally, density of the cavitation pits in the surface increases, and areas of totally removed film allows erosion process to continue into the SS substrate. These findings for TiAlN or AlTiN are in agreement with CE degradation mechanism reported by Krella in works $[7,12]$ for TiN films (deposited by cathodic arc technology). Moreover, surface non-uniformities, such as "scratches" deriving from substrate preparation, acts as surface notches that accelerate perpendicular to substrate cracking of film and its rupture. Cracks usually proceeded along to columnar grains packing. 
However, dominant cavitation erosion mechanism is layer-mode spallation of film which can be related to process of deposition and coatings growth of PVD magnetron sputtered proses. Stainless steel erosion process is much severer than presented for coatings Figure 8, and after $4.5 \mathrm{~h}$ of erosion surface presents developed damage which includes deformation and uniform erosion of surface and is comparable with the literature findings presented in [29-31].
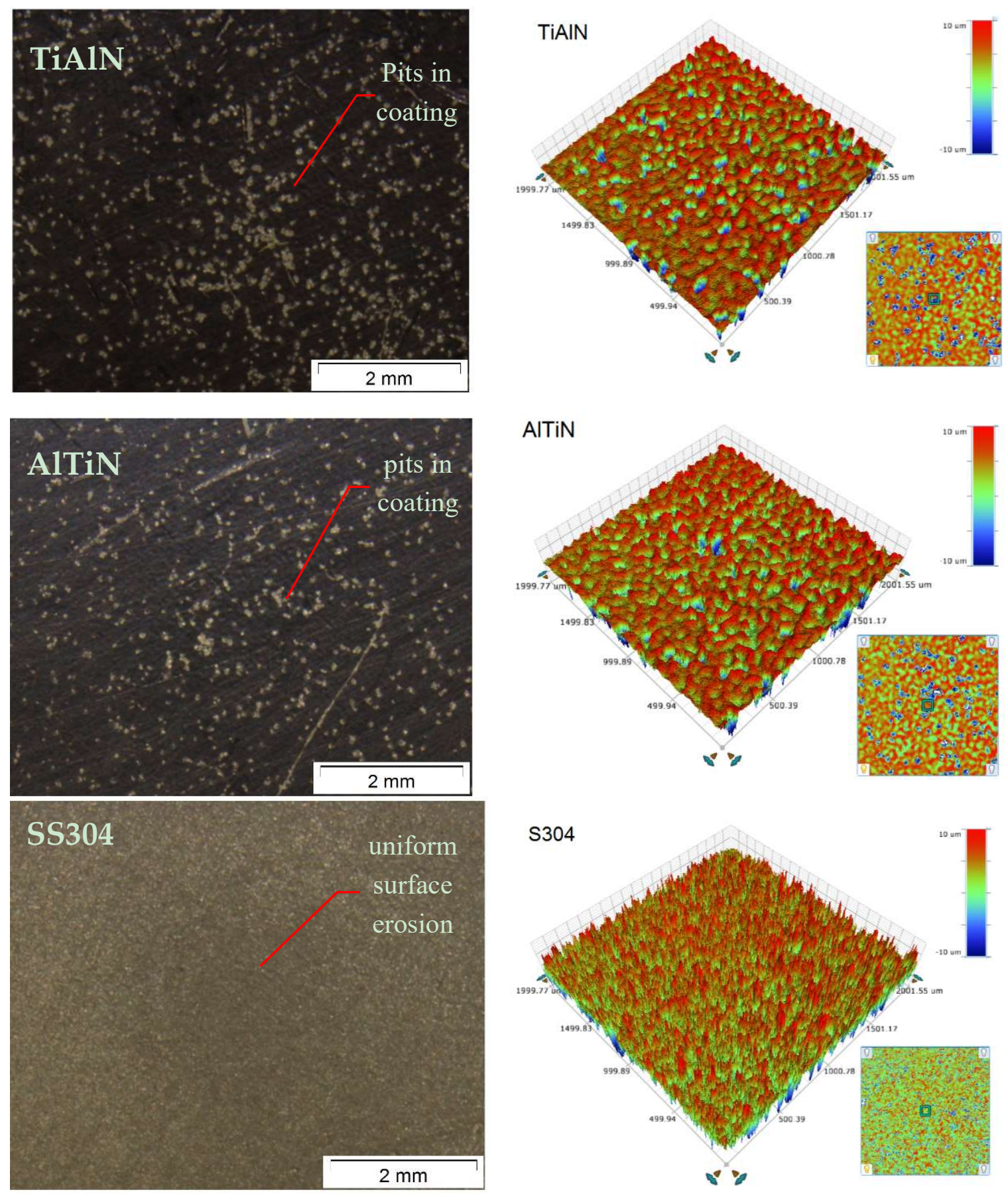

(a)

(b)

Figure 7. Macroscopic view of cavitation erosion worn surface, stereoscopic microscope (a) and roughness profile of tested surfaces (b) after $4.5 \mathrm{~h}$ of cavitation. 


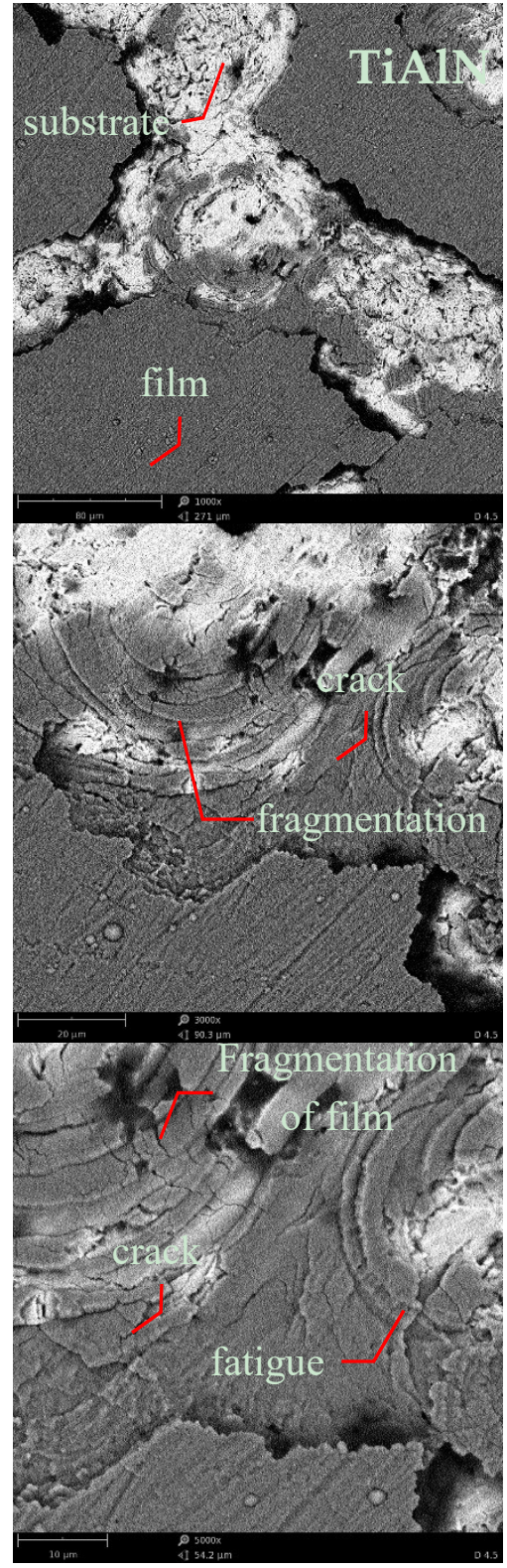

(a)

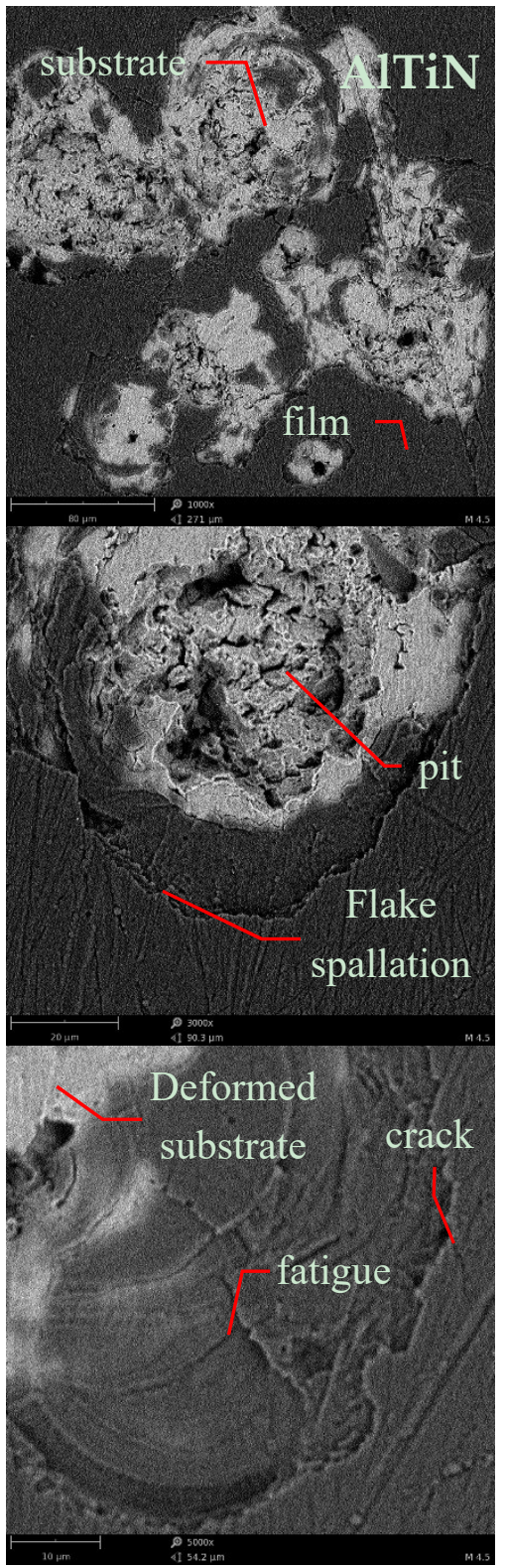

(b)

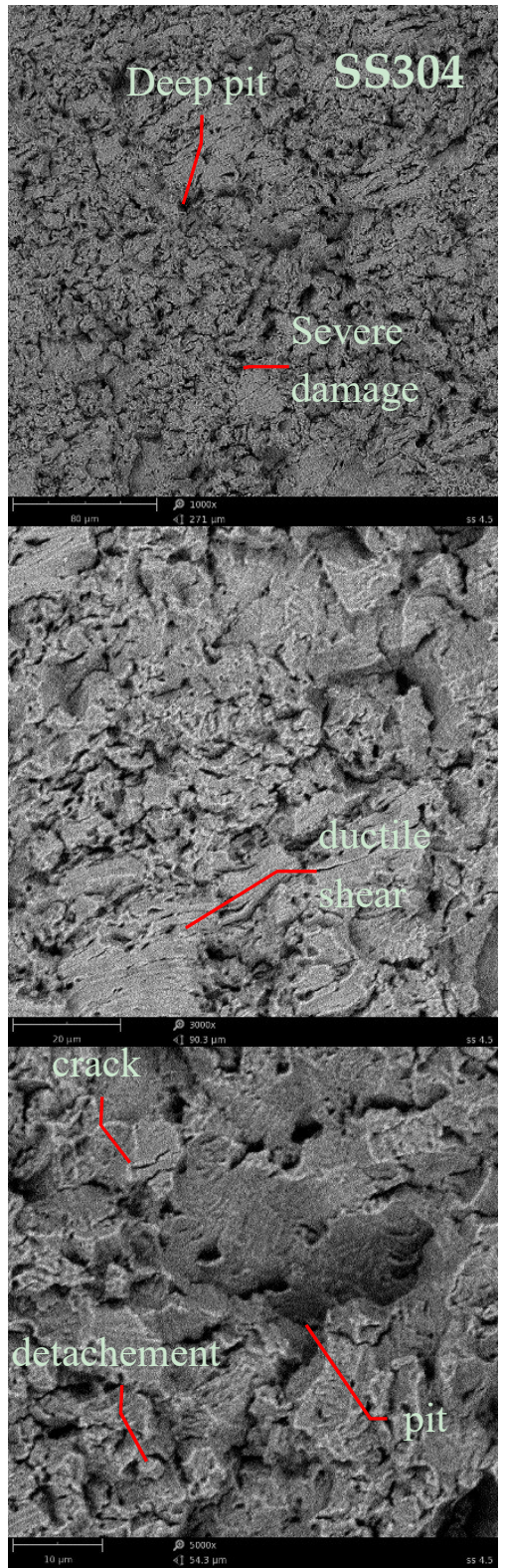

(c)

Figure 8. Comparison of cavitation eroded thin films and stainless steel, after $4.5 \mathrm{~h}$ of testing: column (a) TiAlN; (b) AlTiN; (c) SS304; SEM, 1000×, 3000× and 5000×.

\subsubsection{Effect of cavitation erosion on nanoindentation results}

Nanoindentation measurements seem promising to identify cavitation wear mode. In Figure 9 and Table 3 results of nanoindentation test made before and after cavitation tests are presented, which is quite an approach for cavitation erosion testing of thin films. Stainless steel substrate mechanical properties were measured, and result was analyzed with relation to coated steel. In case of bulk metal alloy, the cavitation effects on increase in hardness as an result of work hardening and/or cavitation load induced phase transformations [27]. In contrary to metal alloys, AlTiN and TiAlN hardness decreases after cavitation erosion experiment. It can be explained by loss of film-substrate adhesion due to cavitation, which finally results in nanoindentation. Moreover scatter of elasticity modulus decreases after cavitation that confirms influence of cavitation on films structure. Also, mechanically damaged by cavitation (material degradation has fatigue character) films cohesion can be affected. It completes the analysis of the cavitation worn surfaces from the SEM photos, given in Figure 8 relating to fatigue process. 
From now on, it seems promising for cavitation erosion mechanism identification to analyze the mechanical properties (Table 3), especially $\mathrm{E} / \mathrm{H}$ and work done, elastic work done estimated before and after cavitation which must be investigated in future. According to literature [13,32,33], susceptibility to elastic strain to failure is expressed by the H/E quotient, as well as its resistance to plastic deformation defined by the $\mathrm{H}^{3} / \mathrm{E}^{2}$ ratio. On the other hand, the results of the $\mathrm{H} / \mathrm{E}$ and $\mathrm{H}^{3} / \mathrm{E}^{2}$ ratio, indicating that the films with the cavitation influenced films exhibited higher values of these ratios, which suggests highly elastic behavior and resistance to plastic deformation [3], in other words AlTiN $\mathrm{H}^{3} / \mathrm{E}^{2}$ ratio presents higher value to TiAlN film, in accordance with normalized CER, Error! Reference source not found., the high value of $\mathrm{H}^{3} / \mathrm{E}^{2}$ coefficient is primarily attributed to fracture toughness of the thin films; hence, the AlTiN coatings are considered to be tougher than TiAlN and finally, much more difficult to be eroded by cavitation.

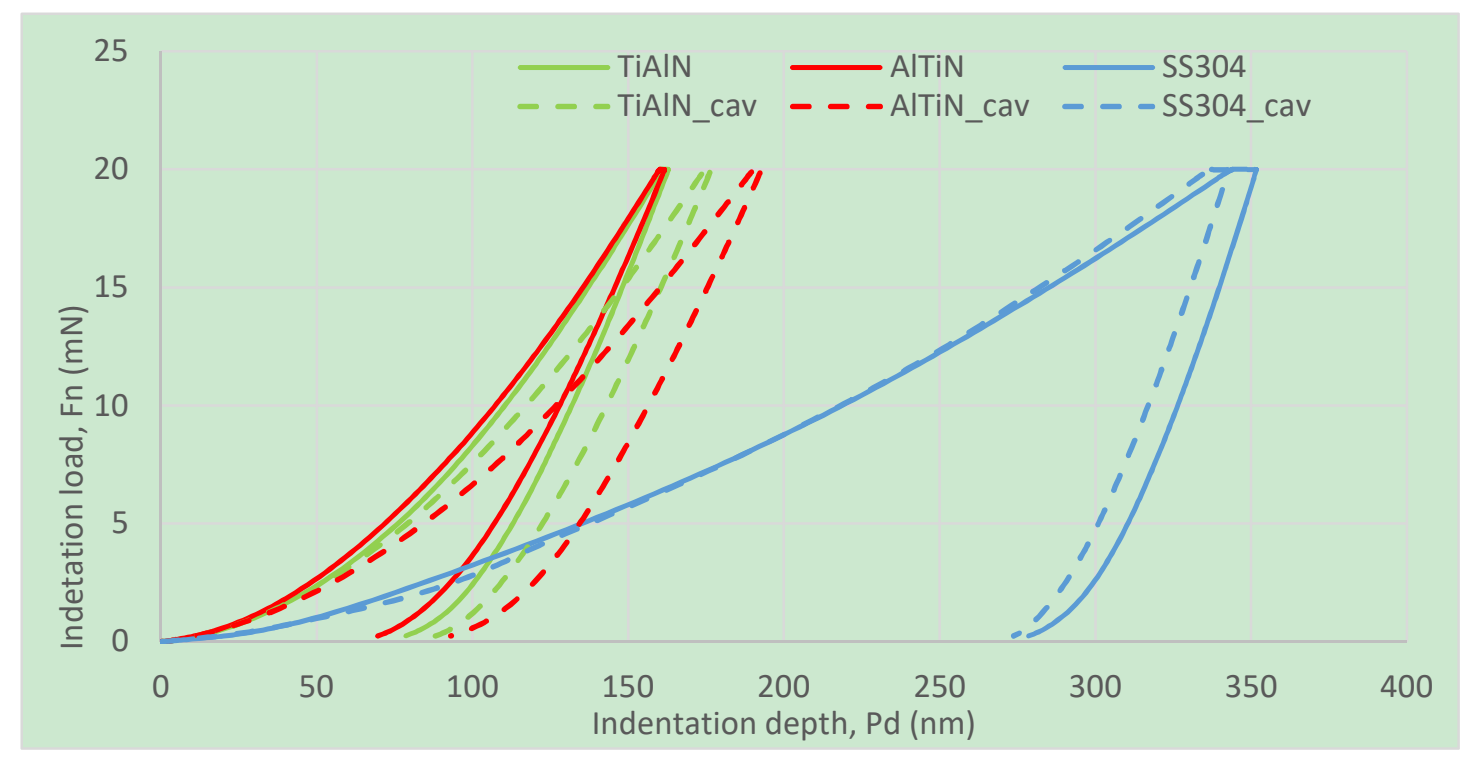

Figure 9. Loading-unloading nanoindentation curves of samples surfaces estimated before and after (marked as "cav") cavitation erosion test.

Table 3. Results of $\mathrm{H}$ - hardness, $E^{*}$-the plane strain modulus and $W_{\text {total }}-$ total work done, $W_{\text {elastic }}-$ lastic work done; measured by nanoindentation on as deposited and affected by cavitation (marked as "cav") stainless steel and film samples.

\begin{tabular}{ccccccc}
\hline Sample & SS304 & SS304_cav & TiAlN & TiAlN_cav & AlTiN & AlTiN_cav \\
\hline$H_{\text {IT (O\&P) }[\mathrm{GPa}]}$ & $8.3 \pm 1.3$ & $8.7 \pm 0.4$ & $54.4 \pm 8.7$ & $49.3 \pm 11.7$ & $59.6 \pm 12.0$ & $41.1 \pm 8.9$ \\
$E^{*}$ (O\&P) [GPa] & $304.3 \pm 41.3$ & $277.6 \pm 13.0$ & $908.6 \pm 205.7$ & $698.8 \pm 144.8$ & $835.0 \pm 151.0$ & $543.7 \pm 101.0$ \\
$H / E$ & 0.027 & 0.031 & 0.060 & 0.071 & 0.071 & 0.077 \\
$H^{3} / E^{2}$ & $2.445 \times 10^{-6}$ & $3.538 \times 10^{-6}$ & $3.945 \times 10^{-6}$ & $7.123 \times 10^{-6}$ & $6.101 \times 10^{-6}$ & $1.051 \times 10^{-5}$ \\
$W_{\text {total }}[\mathrm{pJ}]$ & $2892.5 \pm 250.6$ & $2722.2 \pm 78.3$ & $1174.8 \pm 124.6$ & $1314.1 \pm 121.5$ & $1203.3 \pm 113.9$ & $1463.3 \pm 145.7$ \\
$W_{\text {elastic }}[\mathrm{pJ}]$ & $555.0 \pm 22.3$ & $559.1 \pm 17.1$ & $668.8 \pm 41.9$ & $721.8 \pm 26.1$ & $732.2 \pm 40.7$ & $785.1 \pm 44.5$ \\
\hline
\end{tabular}

\subsection{Sliding Wear Behaviour (Ball-on-Disc Test)}

TiAlN and AlTiN films can be easily applied on various substrates and are poplar in machine building especially, while producing or regenerating cutting tools. It is known that these coatings resist high temperature and severe load working conditions. However, its wear mechanism under low load sliding conditions was not reported sufficiently in the literature. In other words, wear in light load with moderate hardness of counter ball-simulates low friction conditions of operation parameters of real components performance. Thus, quantitative results of sliding wear test are given in Table 4 and Figure 10. The study has shown that both films presents superior sliding wear results to reference stainless steel sample. Also, TiAlN presents slightly higher average value of wear resistance than AlTiN which can be ascribed to TiAlN film hardness, Figure 5. However, generally 
films $\mathrm{K}$ and $\mu$ parameters are at the comparable level (in range of SD, see Table 4). In general, in most engineering applications, the higher are the $H / E$ and $H^{3} / E^{2}$ coefficients, the greater the wear resistance the coating should represent $[13,32,33]$. That was confirmed in this study by higher wear of stainless steel than PVD coatings, see results in Table 4. Furthermore, qualitative evaluation indicates that the SS304 typically presents severe sliding wear Figures 10 and 11 in comparison to samples with deposited TiAlN (Figure 12) and AlTiN (Figure 13). For stainless steel adhesive sliding wear mode and plastic deformation, ploughing with smearing, wear debris oxidation and grooving were recognized (Figure 11). Also, due to repeated upsetting and deformation of the material, as an effect of low cycle fatigue, flake shape delamination with debris transfer are clearly visible.

In turn, due to films superior hardness and resistance to oxidation, coatings wear mechanism can be classified as grooving and microscratching with a presence of long scratches (TiAlN Figure 12 and AlTiN Figure 13), which is quite similar to elongated scratches recognized after sliding test of hard $\mathrm{CoCr}$ metal alloys [19]. Additionally, microploughing can be seen at the edges of the wear traces of both films. Thus, after the nano-tribo test, films are pressed toward the SS substrate and no delamination can be observed and transfer of debris through the sliding wear trace. It can be deduced from comparing films structure Figure 2 with the wear trace observed at higher magnification, see Figure 14, that sliding results at smearing the top hills of columnar grains. To sum up, comparable sliding wear mechanisms were stated for both films.

Table 4. Sliding wear results for films and reference SS304 sample (mean \pm SD).

\begin{tabular}{ccc}
\hline Sample & Wear Factor, $\mathbf{K}\left(\mathbf{m m} 3 \mathbf{~ N}^{-\mathbf{1}} \mathbf{~ m}^{-\mathbf{1}}\right)$ & Coefficient of Friction, $\boldsymbol{\mu}$ \\
\hline TiAlN & $1.35 \times 10^{-5} \pm 4.36 \times 10^{-6}$ & $0.319 \pm 0.037$ \\
AlTiN & $2.09 \times 10^{-5} \pm 3.49 \times 10^{-6}$ & $0.340 \pm 0.031$ \\
SS304 & $50.17 \times 10^{-5} \pm 61.52 \times 10^{-6}$ & $0.628 \pm 0.088$ \\
\hline
\end{tabular}

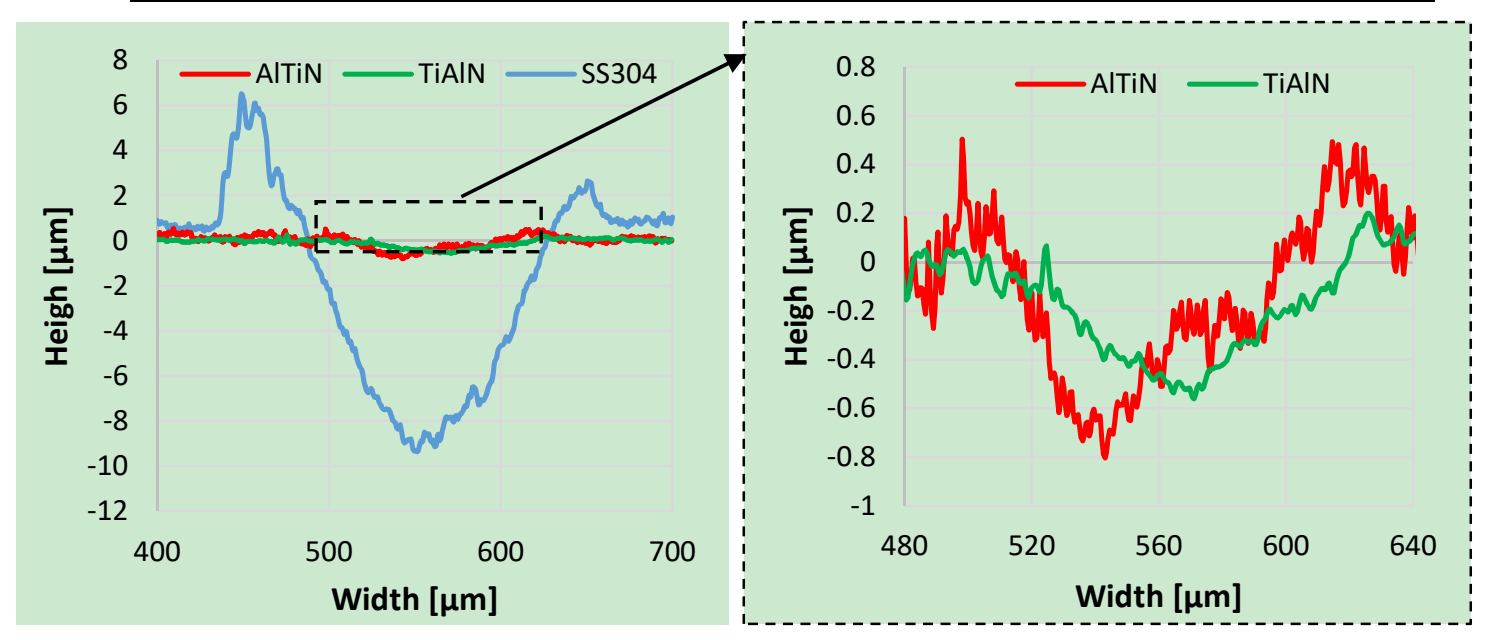

(a)

(b)

Figure 10. Sliding wear profiles: (a) films and stainless steel sample; (b) enlarged selected area of TiAlN and AlTiN wear traces from (a). 


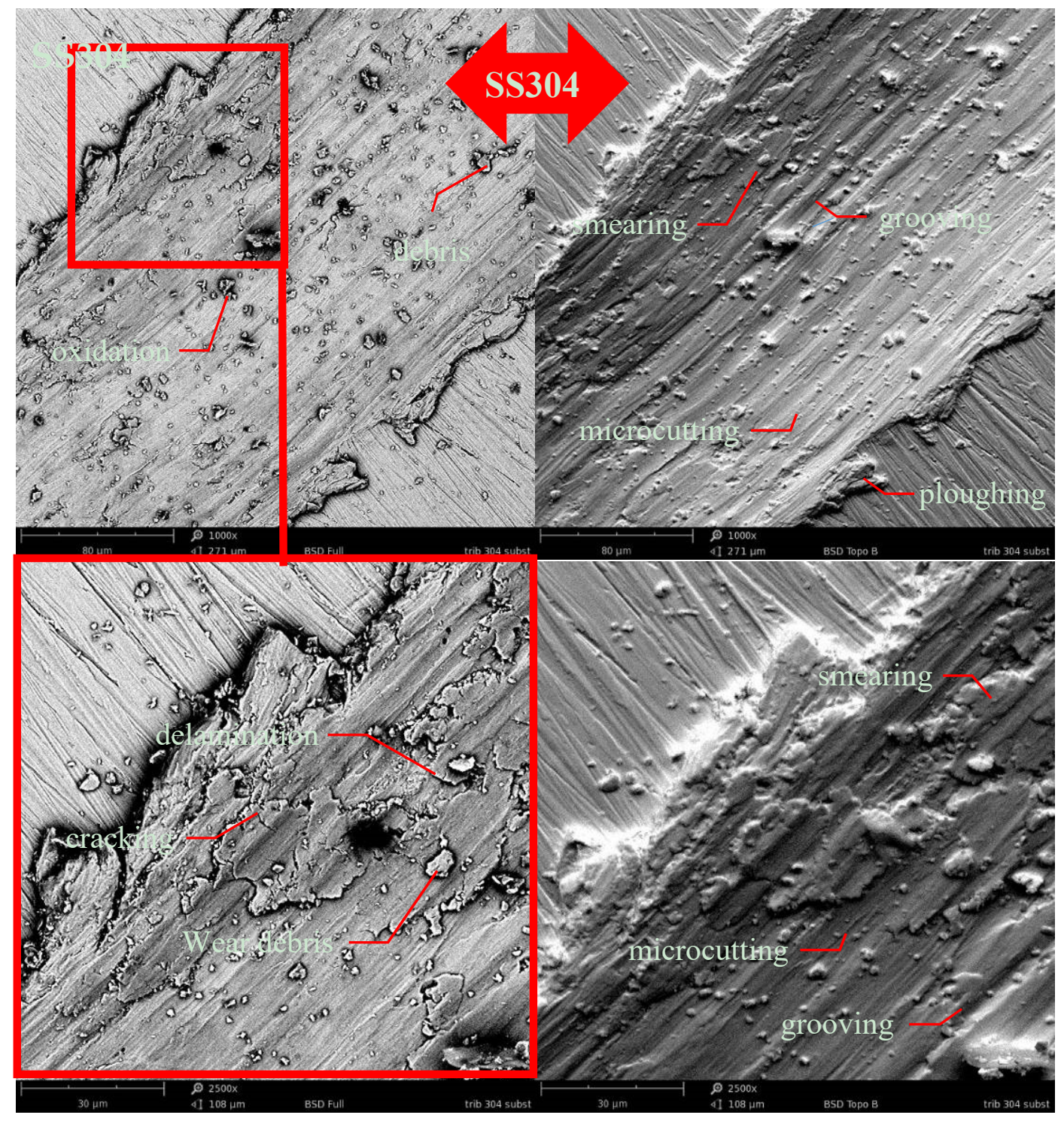

(a)

(b)

Figure 11. Wear trace on the SS304 sample: (a) SEM-BSD; and (b) SEM-topo, 1000× and 2500×.

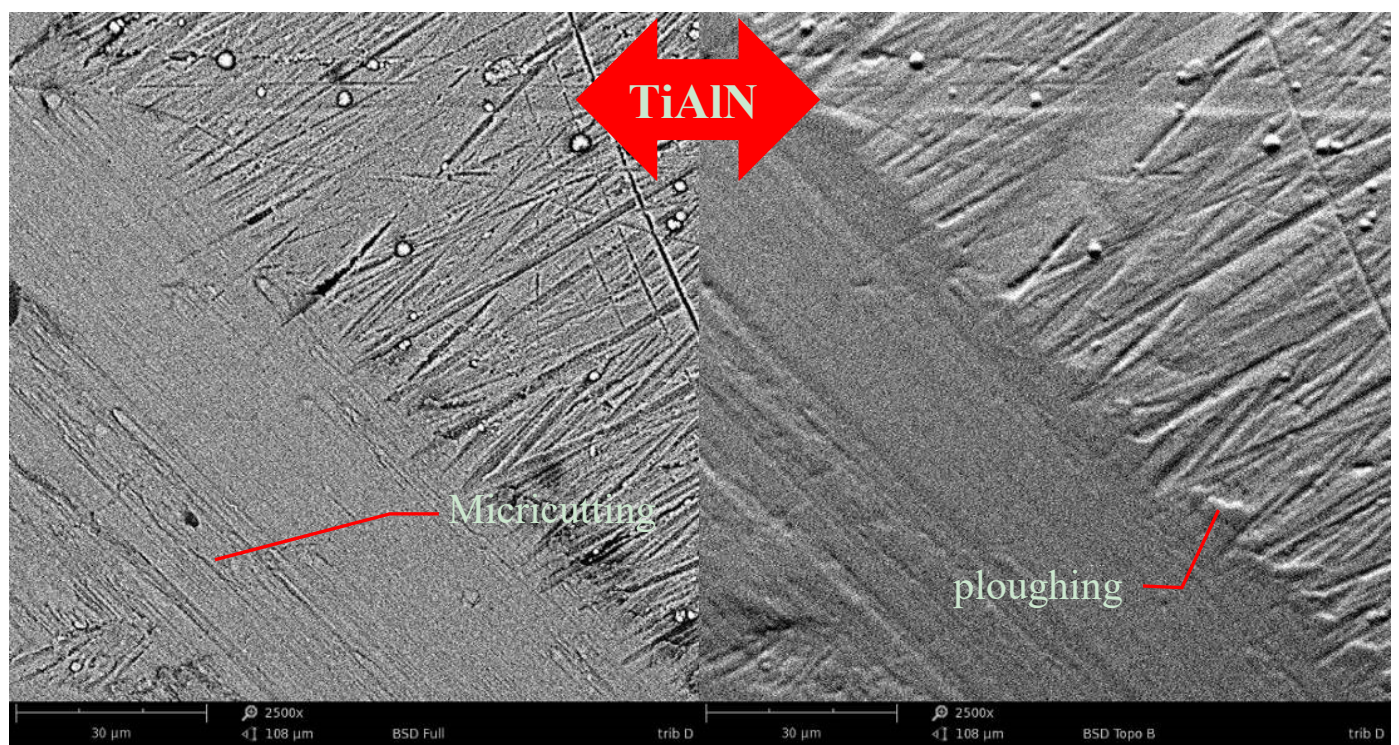

(a)

(b) 
Figure 12. Wear trace on the TiAlN film: (a) SEM-BSD and (b) SEM-topo, 2500×.

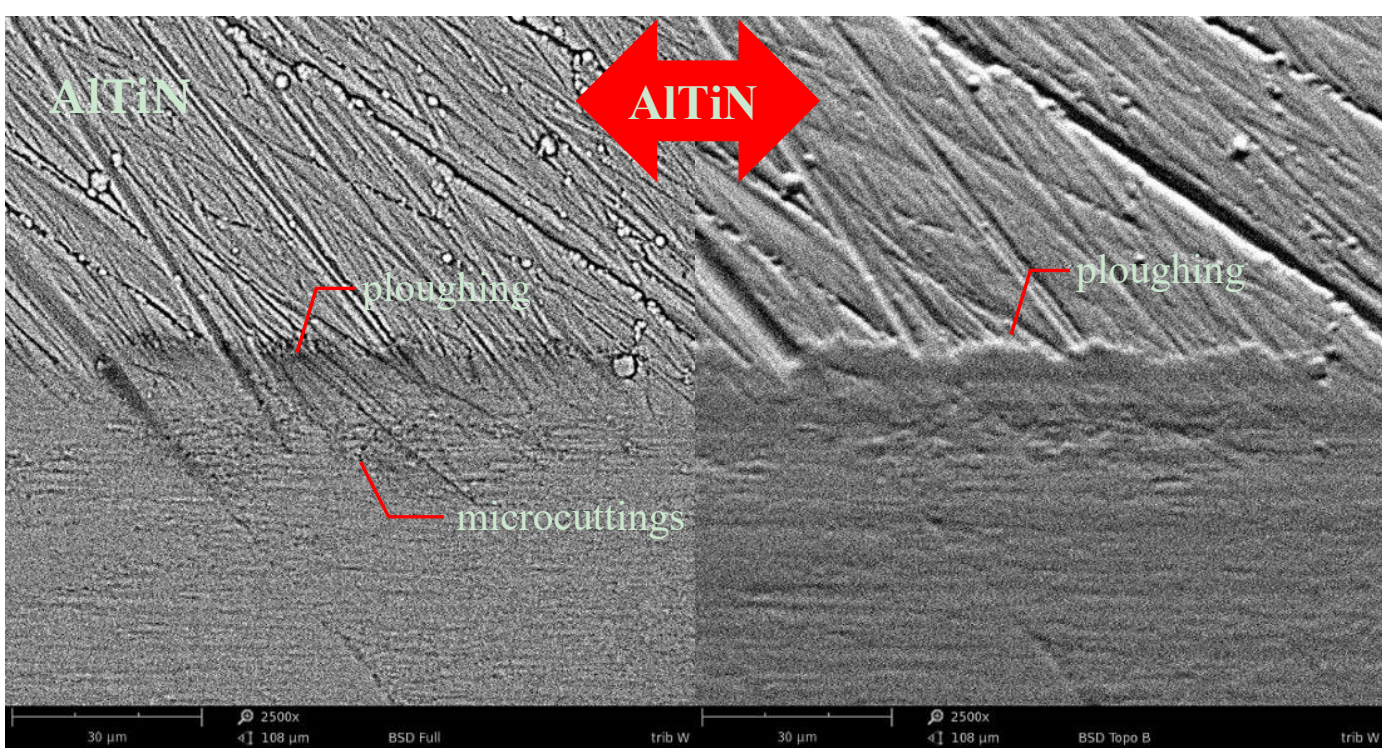

(a)

Figure 13. Wear trace on the AlTiN film: (a) SEM-BSD and (b) SEM-topo, 1000× and 2500×.

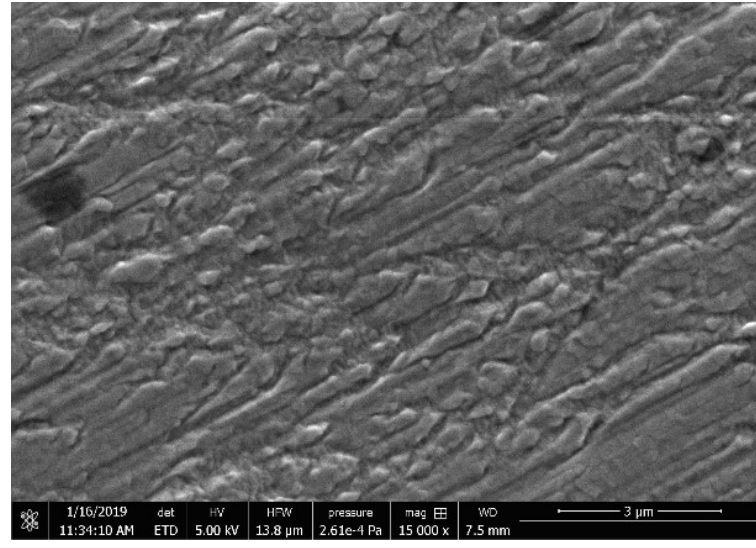

(a)

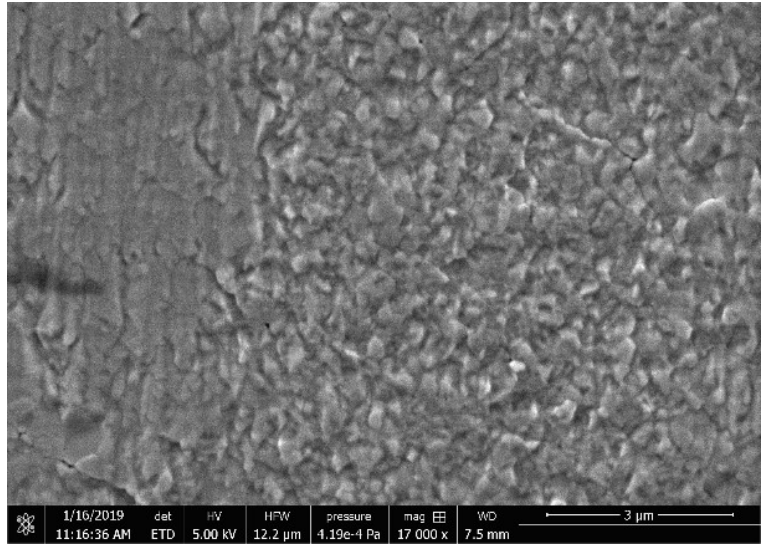

(b)

Figure 141. Sliding wear trace: (a) TiAl; SEM, 15,000×; and (b) AlTiN; SEM, 17,000×.

\section{Conclusions}

The stainless steel is applied for different components and considered as structural metal with moderate resistance for cavitation erosion. Thus, application of PVD coatings is proposed as an easy to implement in industry practice and a promising attempt for wear prevention of stainless steel parts. In the present work, the cavitation erosion and sliding wear mechanisms of magnetron sputtered AlTiN and TiAlN coatings deposited on SS304 stainless steel (SS) were investigated. The following conclusions can be drawn:

- The properties of films acknowledged that coatings present satisfying structure, i.e., typical columnar morphology, Sa roughness parameter bellow value of $0.2 \mu \mathrm{m}$ and varies in thickness $\approx 2.7 \mu \mathrm{m}$ for TiAlN and $\approx 3.8 \mu \mathrm{m}$ for AlTiN. Also, Rockwell and scratch tests of films indicate satisfactory adhesion to the steel substrate although, higher force of Lc2 parameters for AlTiN than TiAlN suggests that AlTiN adhered strongly to substrate. AlTiN film was tougher i.e. exhibited higher H/E parameter than TiAlN.

- Cavitation erosion resistance for AlTiN was almost one third higher than TiAlN films and superior almost ten times than SS304 sample. The influence of films structural and mechanical 
properties, i.e., hardness, adhesion and elastic modulus, on cavitation erosion resistance was acknowledged.

- Cavitation erosion mechanism of both AlTiN and AlTiN coatings presents a brittle manner and relies on fatigue processes that result in coating rupture and spallation. However, comparison of cavitation worn TiAIN and AlTiN films allows to claim higher level of fragmentation for TiAlN film than AlTiN, which finally accelerates wear of TiAlN films. Additionally, films nanoindentation results measured before and after cavitation testing indicate changes in coatings structure, that acknowledged wear mechanism that starts with coating internal delamination in flake spallation mode.

- Sliding wear of uncoated SS304 sample was much severe than after PVD coatings deposition. Resistance to sliding wear of AlTiN and TiAlN was more than 24 times higher than stainless steel sample. Additionally, deposition of PVD films onto stainless steel substrate decreases almost twice the friction coefficient. Sliding wear mechanism of both AlTiN and TiAlN films relies on grooving, micro-scratching and micro-ploughing.

- It was confirmed that various fluid machinery components made from austenitic stainless steel that undergo cavitation erosion can be with prevented by depositing AlTiN and TiAlN films.

Author Contributions: Conceptualization, M.Sz.; Methodology, M.Sz; Formal Analysis, M.Sz. and M.W.; Investigation, M.Sz, K.P. and M.K.; Writing-Original Draft Preparation, M.Sz.; Writing-Review \& Editing, M.Sz.; Visualization, M.Sz., K.P. and M.K.; Supervision, M.Sz. and M.W.

Conflicts of Interest: The authors declare no conflict of interest.

\section{References}

1. Ha, H.-Y.; Jang, J.H.; Lee, T.-H.; Won, C.; Lee, C.-H.; Moon, J.; Lee, C.-G. Investigation of the Localized Corrosion and Passive Behavior of Type 304 Stainless Steels with 0.2-1.8 wt \% B. Materials 2018, 11, 2097.

2. Szala, M.; Beer-Lech, K.; Walczak, M. A study on the corrosion of stainless steel floor drains in an indoor swimming pool. Eng. Fail. Anal. 2017, 77, 31-38.

3. España P., C.L.; Recco, A.A.C.; Olaya, J.J. A Microstructural and Wear Resistance Study of Stainless SteelAg Coatings Produced through Magnetron Sputtering. Coatings 2018, 8, 381.

4. Ha, H.-Y.; Lee, T.-H.; Bae, J.-H.; Chun, D.W. Molybdenum Effects on Pitting Corrosion Resistance of FeCrMnMoNC Austenitic Stainless Steels. Metals 2018, 8, 653.

5. Pitting Corrosion of the Resistance Welding Joints of Stainless Steel Ventilation Grille Operated in Swimming Pool Environment Available online: https://www.hindawi.com/journals/ijc/2018/9408670/ (accessed on Feb 22, 2019).

6. Wang, P.; Zhang, Y.; Yu, D. Microstructure and Mechanical Properties of Pressure-Quenched SS304 Stainless Steel. Materials 2019, 12, 290.

7. Krella, A.K. The new parameter to assess cavitation erosion resistance of hard PVD coatings. Eng. Fail. Anal. 2011, 18, 855-867.

8. Subramanian, B.; Umamaheswari, G.; Jayachandran, M. Properties and corrosion behaviour of reactive magnetron sputtered TiAIN coatings on AISI 316L SS in simulated bodily fluid. Corros. Eng. Sci. Technol. 2007, 42, 349-355.

9. Hans, M.; Patterer, L.; Music, D.; Holzapfel, D.M.; Evertz, S.; Schnabel, V.; Stelzer, B.; Primetzhofer, D.; Völker, B.; Widrig, B.; et al. Stress-Dependent Elasticity of TiAlN Coatings. Coatings 2019, 9, 24.

10. Kulkarni, A.P.; Sargade, V.G. Characterization and Performance of AlTiN, AlTiCrN, TiN/TiAlN PVD Coated Carbide Tools While Turning SS 304. Mater. Manuf. Process. 2015, 30, 748-755.

11. Kohlscheen, J.; Bareiss, C. Effect of Hexagonal Phase Content on Wear Behaviour of AlTiN Arc PVD Coatings. Coatings 2018, 8, 72 .

12. Krella, A.; Czyżniewski, A. Cavitation erosion resistance of nanocrystalline TiN coating deposited on stainless steel. Wear 2008, 265, 963-970.

13. Łępicka, M.; Grądzka-Dahlke, M.; Pieniak, D.; Pasierbiewicz, K.; Kryńska, K.; Niewczas, A. Tribological performance of titanium nitride coatings: A comparative study on TiN-coated stainless steel and titanium alloy. Wear 2019, 422-423, 68-80. 
14. ASTM G32-10: Standard Test Method for Cavitation Erosion Using Vibratory Apparatus; ASTM International: West Conshohocken: PA, USA, 2010;

15. Szala, M.; Hejwowski, T. Cavitation Erosion Resistance and Wear Mechanism Model of Flame-Sprayed Al2O3-40\%TiO2/NiMoAl Cermet Coatings. Coatings 2018, 8, 254.

16. Szala, M. Application of computer image analysis software for determining incubation period of cavitation erosion - preliminary results. 2017, 15, 06003.

17. Budzyński, P.; Kamiński, M.; Wiertel, M.; Pyszniak, K.; Droździel, A. Mechanical Properties of the Stellite 6 Cobalt Alloy Implanted with Nitrogen Ions. Acta Phys. Pol. A 2017, 132, 203-205.

18. Kamiński, M.; Budzyński, P.; Szala, M.; Turek, M. Tribological properties of the Stellite 6 cobalt alloy implanted with manganese ions. IOP Conf. Ser. Mater. Sci. Eng. 2018, 421, 032012.

19. Walczak, M.; Pieniak, D.; Niewczas, A.M. Effect of recasting on the useful properties CoCrMoW alloy. Eksploat. Niezawodn. - Maint. Reliab. 2014, 16, 330-336.

20. Kalss, W.; Reiter, A.; Derflinger, V.; Gey, C.; Endrino, J.L. Modern coatings in high performance cutting applications. Int. J. Refract. Met. Hard Mater. 2006, 24, 399-404.

21. Özkan, D. Friction Behavior of TiAlN, AlTiN and AlCrN Multilayer Coatings at Nanoscale. Erzincan Üniversitesi Fen Bilim. Enstitüsü Derg. 2018, 11, 451-458.

22. Krella, A. The influence of TiN coatings properties on cavitation erosion resistance. Surf. Coat. Technol. 2009, 204, 263-270.

23. Szala, M.; Dybowski, B.; Hejwowski, T.J.; Kiełbus, A. The mechanisms of cavitation erosion of the Elektron21 magnesium alloy. Solid State Phenom. 2015, 229, 99-104.

24. Dybowski, B.; Szala, M.; Hejwowski, T.J.; Kiełbus, A. Microstructural phenomena occurring during early stages of cavitation erosion of Al-Si aluminium casting alloys. Solid State Phenom. 2015, 227, 255-258.

25. Szala, M.; Hejwowski, T. Cavitation erosion resistance of coating flame deposited with nickel base powder. Przeglad Spaw. - Weld. Technol. Rev. 2015, 87, 36-41.

26. Szala, M.; Hejwowski, T.; Lenart, I. Cavitation erosion resistance of Ni-Co based coatings. Adv. Sci. Technol. Res. J. 2014, 8, 36-42.

27. Szala, M. Coatings for increasing cavitation wear resistance of machine parts and elements; Doctoral degree thesis; Lublin University of Technology, Poland: Poland, 2016;

28. Szala, M.; Walczak, M. Cavitation erosion and sliding wear resistance of HVOF coatings. Weld. Technol. Rev. 2018, 90 .

29. Hattori, S.; Mikami, N. Cavitation erosion resistance of stellite alloy weld overlays. Wear 2009, 267, 19541960.

30. Wu, Y.; Hong, S.; Zhang, J.; He, Z.; Guo, W.; Wang, Q.; Li, G. Microstructure and cavitation erosion behavior of WC-Co-Cr coating on $1 \mathrm{Cr} 18 \mathrm{Ni}$ Ti stainless steel by HVOF thermal spraying. Int. J. Refract. Met. Hard Mater. 2012, 32, 21-26.

31. Mesa, D.H.; Garzón, C.M.; Tschiptschin, A.P. Influence of cold-work on the cavitation erosion resistance and on the damage mechanisms in high-nitrogen austenitic stainless steels. Wear 2011, 271, 1372-1377.

32. Solis, J.; Zhao, H.; Wang, C.; Verduzco, J.A.; Bueno, A.S.; Neville, A. Tribological performance of an H-DLC coating prepared by PECVD. Appl. Surf. Sci. 2016, 383, 222-232.

33. Leyland, A.; Matthews, A. On the significance of the H/E ratio in wear control: a nanocomposite coating approach to optimised tribological behaviour. Wear 2000, 246, 1-11.

(C) 2019 by the authors. Licensee MDPI, Basel, Switzerland. This article is an open access article distributed under the terms and conditions of the Creative Commons Attribution (CC BY) license (http://creativecommons.org/licenses/by/4.0/). 